\title{
Morbidity and mortality of bone metastases in advanced adrenocortical carcinoma: a multicenter retrospective study
}

\author{
Alfredo Berruti' ${ }^{1}$ Rossella Libè ${ }^{2}$, Marta Laganà', Hester Ettaieb ${ }^{3}$, Mohamad Anas Sukkarii, Jérôme Bertherat' ${ }^{2}$, \\ Richard A Feelders ${ }^{5}$, Salvatore Grisantii', Jérôme Cartry ${ }^{6}$, Gherardo Mazziotti ${ }^{7}$, Sandra Sigala ${ }^{8}$, Eric Baudin ${ }^{6}$, \\ Harm Haak ${ }^{3,9}$, Mouhammed Amir Habra ${ }^{4}$ and Massimo Terzolo ${ }^{10}$
}

${ }^{1}$ Department of Medical and Surgical Specialties, Radiological Sciences and Public Health, Medical Oncology Unit, University of Brescia at ASST Spedali Civili, Brescia, Italy, ${ }^{2}$ Department of Endocrinology and Metabolic Diseases, Hôpital Cochin, Paris, France, ${ }^{3}$ Department of Internal Medicine, Maxima Medisch Centrum Eindhoven/Veldhoven, Maastricht University, CAPHRI School for Public Health and Primary Care, Ageing and Long-Term Care, Maastricht, the Netherlands, ${ }^{4}$ The University of Texas MD Anderson Cancer Center, Houston, Texas, USA, ${ }^{5}$ Erasmus Medical Center, Department of Internal Medicine, Academic Expertise Center for Adrenal and Neuroendocrine Tumors, Rotterdam, the Netherlands, ${ }^{6}$ Department of Nuclear Medicine and Endocrine Oncology, Gustave Roussy Cancer Center, Villejuif, France, ${ }^{7}$ Department of Biomedical Sciences Humanitas University and Endocrine and Andrology Unit, Humanitas Clinical and Research, Milan, Italy, ${ }^{8}$ Section of Pharmacology, Department of Molecular and Translational Medicine, University of Brescia, Brescia, Italy, ${ }^{9}$ Division of General Internal Medicine, Department of Internal Medicine, Maastricht University Medical Centre+, Maastricht, the Netherlands, and ${ }^{10}$ Internal Medicine, Department of Clinical and Biological Sciences, San Luigi Gonzaga Hospital, Orbassano, University of Turin, Turin, Italy

Correspondence should be addressed to A Berruti

Email alfredo.berruti@unibs.it

\section{Abstract}

Introduction: Adrenocortical carcinoma (ACC) is a rare cancer that commonly spreads to the liver, lungs and lymph nodes. Bone metastases are infrequent.

Objective: The aim of this report was to describe the clinical characteristics, survival perspective, prognostic factors and frequency of adverse skeletal-related events (SREs) in patients with ACC who developed bone metastasis.

Methods: This is a retrospective, observational, multicenter, multinational study of patients diagnosed with bone metastases from ACC who were treated and followed up in three European countries (France, Italy and The Netherlands) and one center in the United States.

Results: Data of 156 patients were captured. The median overall survival was 11 months. SREs occurred in $47 \%$ of patients: $17 \%$ bone fractures, $17 \%$ spinal cord compression, $1 \%$ hypercalcemia, $12 \%$ developed more than one SRE. In multivariate analysis, cortisol hypersecretion was the only prognostic factor significantly associated with a higher mortality risk (hazard ratio (HR) 2.24, 95\% confidence interval $(\mathrm{Cl}): 1.19-4.23, P=0.013$ ) and with the development of a SREs (of border line significance). The administration of antiresorptive therapies (bisphosphonates and denosumab) was associated with a lower risk of death, even if not significant, and their survival benefit appeared confined in patients attaining serum mitotane levels within the therapeutic range.

Conclusion: Bone metastases in ACC patients are associated with poor prognosis and high risk of SREs. Cortisol hypersecretion was the only prognostic factor suggesting a potential benefit from antisecretory medications. The therapeutic role of bisphosphonates and denosumab to improve patient outcome deserves to be tested in a prospective clinical trial. 


\section{Introduction}

Adrenocortical carcinoma (ACC) is a rare and aggressive malignant tumor, with an incidence of 0.5-2.0 new cases per million population per year $(1,2)$. The mainstay of treatment is surgery $(1,2,3)$; however, many patients with radically resected disease are destined to relapse and die from disease $(1,2,3,4)$. Patients with metastatic disease have a poor prognosis and their 5-year survival is less than $15 \%(1,2)$.

Bone metastases are not frequently reported in ACC. In a large European Network for the Study of Adrenal Tumors (ENSAT) study, involving 444 patients with stage IV ACC, bone metastases (BM) were observed in 32 patients only (7\%) (5). Although rare, ACC patients with metastatic bone disease deserve attention since bone involvement has been reported to greatly impair the quality of life in cancer patients due to bone pain and adverse skeletalrelated events (SREs), such as pathological fractures, spinal cord and nerve root compressions and hypercalcemia (6). In addition, the occurrence of SREs in solid tumors is frequently associated with a grim prognosis (7).

Actually, there are no data available on the natural history of ACC patients with BM, the frequency and distribution of SREs and the prognostic parameters.

Moreover, several prospective randomized clinical trials have demonstrated that bone resorption inhibitors, such as bisphosphonates and denosumab, significantly reduce the risk of SREs in bone metastatic patients from prostate, breast, lung and other primary malignancies $(8,9,10)$.

No data are available on the efficacy of bone resorption inhibitors in the management of ACC patients with BM. However, on the basis of published data $(11,12,13)$, these drugs are used currently in ACC patients in the routine clinical practice.

This multicenter, multinational study was undertaken to obtain information on the natural history of BM from ACC and their clinical management. The primary aim was to define the overall survival of this population, secondary aims were (1) frequency and type of SREs, (2) prognostic factors, (3) efficacy of bone resorption inhibitors in the SRE prevention and disease outcome.

\section{Patients and methods}

\section{Study design}

This was a retrospective, observational, multicenter study in which medical records of patients diagnosed with BM from ACC who were treated and followed up in referral centers in three European countries (France, Italy and The Netherlands) and one US center were analyzed. Data were collected from adult patients of all ages who received standard treatments in accordance with their treating physician practice and multidisciplinary tumor board practice. Only patients with ACC who had at least one bone metastasis during their disease course, as identified by bone scan or other imaging assessment (e.g. standard $\mathrm{X}$-rays, computed tomography scans, PET-TC or magnetic resonance imaging of the skeleton), were included in the study. Patients with bone invasion by contiguity were excluded.

Data collected at baseline and throughout the disease history included: Weiss score, Ki67, ENSAT stage at ACC diagnosis, time from diagnosis till the onset of BM, extraskeletal disease sites: local, visceral metastases, lymph-node involvement, hormonal status: presence/absence and type of hormone secretion, time to progression, time to the onset of first SRE and overall survival from the diagnosis of BM, type of SRE (bone fracture, hypercalcemia, spinal cord compression), radiation therapy in bone, skeletal surgery, treatment with bisphosphonates or denosumab.

The ENSAT registry was approved by the local ethics committees (Comitato Etico Provinciale Provincia di Brescia c/o Spedali Civili, Comité de protection des personnes Ile de France IV, METC, Medical Ethical Review Committee, Máxima Medisch Centrum Veldhoven); the study was also approved by The University of Texas MD Anderson Cancer Center's institutional review board. All patients included had given their written informed consent.

\section{Statistical analysis}

The primary end-point was overall survival in this patient population, which was defined as the time interval between the date of diagnosis of $\mathrm{BM}$ and the date of death or the last known alive date. The time between primary diagnosis and occurrence of $\mathrm{BM}$ and the time to the occurrence of SRE from the diagnosis of BM were also evaluated as secondary end points. Descriptive statistics were used for patient demographics, tumor characteristics and frequency of SREs. Categorized variables were expressed as percentages.

The time to first SRE was defined as the interval between date of diagnosis of BM to the first occurrence of either clinical bone fracture, spinal cord compression or hypercalcemia. Patients without SREs were censored at the last follow-up or death. 
All survival curves were calculated by the KaplanMeier method and differences compared by the log-rank test. The Cox's proportional hazards regression model was employed to assess the hazard ratios (HRs) and 95\% confidence intervals (95\% CIs) both in the univariate and multivariate analysis, with the lowest risk group as the reference group. The parameters associated with OS or time to SRE in the univariate analysis (at $P \leq 0.10$ ) were included in the multivariate analysis model.

Heterogeneity in the effect of bisphosphonate/ denosumab therapy in subgroups of patients was evaluated with the use of standard tests for interaction. Missing data were dealt with by excluding patients from particular analyses if their files did not contain data for the required variables. All reported $P$ values are two-sided and $P$ values less than 0.05 were considered to indicate statistical significance.

SPSS statistical software (version 17.00) was used for statistical analysis. A $P$ value of 0.05 was considered statistically significant. Due to the absence of any published data on the clinical outcome of bone metastatic ACC and the explorative nature of this study, a formal calculation of the sample size was not performed. It was considered, however, that a minimum of 100 patients would have been required to have an adequate power for statistical analyses.

\section{Results}

\section{Patient characteristics and treatment administered}

Data of a total number of 156 ACC patients with BM were captured: 59 from Gustave Roussy and Cochin hospitals in Paris (France), 17 from Medical Oncology Unit in Brescia and Internal Medicine in Orbassano (Italy), 21 from several centers in Netherlands and 59 from University of Texas MD Anderson Cancer Center in the United States. These patients were identified from 1995 to 2016 after reviewing the records of 1129 ACC patients with metastatic disease followed in the participating institutions. The proportion of bone involvement in metastatic ACC in this series was $13.8 \%(156 / 1129)$. Patient demography and tumor characteristics are described in Table 1.

The median age was 53 years, male/female ratio was $1 / 2(51 / 105)$. Sixty/156 (38\%) had bone metastasis at the time of ACC diagnosis and 95/155 (61\%) developed bone metastasis during follow-up. Ninety-seven out of 154 assessable patients (62\%) had hormone hypersecretion,
Table 1 Patient and tumor characteristics.

\begin{tabular}{|c|c|}
\hline Characteristics & Values \\
\hline$n$ & 156 \\
\hline Age: median (range) & $53(17-87)$ \\
\hline \multicolumn{2}{|l|}{ Gender } \\
\hline Male & $51(33 \%)$ \\
\hline Female & $105(67 \%)$ \\
\hline \multicolumn{2}{|l|}{ Extraskeletal disease sites } \\
\hline Lung & $91(59 \%)$ \\
\hline Liver & $83(54 \%)$ \\
\hline Lymphnodes & $41(27 \%)$ \\
\hline Other & $40(25 \%)$ \\
\hline \multicolumn{2}{|l|}{ Number of metastatic sites } \\
\hline Bone only & $14(9 \%)$ \\
\hline 2 metastatic sites & $61(39 \%)$ \\
\hline More than two sites & $76(49 \%)$ \\
\hline Hormone secretion profile & $97(62 \%)$ \\
\hline No secretion & $57(37 \%)$ \\
\hline Missing & $2(1 \%)$ \\
\hline Only cortisol & $46(29 \%)$ \\
\hline Cortisol + androgens & $18(12 \%)$ \\
\hline $\begin{array}{l}\text { Cortisol ( } \pm \text { androgens) + other } \\
\text { hormones }\end{array}$ & $17(11 \%)$ \\
\hline Androgens only & $12(8 \%)$ \\
\hline Estrogens only & $1(1 \%)$ \\
\hline Mineral-corticoids only & 0 \\
\hline \multicolumn{2}{|l|}{ Bone metastases } \\
\hline Synchronous & $60(38 \%)$ \\
\hline Metachronous & 95 (61\%) \\
\hline Missing & $1(1 \%)$ \\
\hline \multicolumn{2}{|c|}{ Time to onset bone metastases from ACC diagnosis (months) } \\
\hline Median (range) & $6(0-122)$ \\
\hline \multicolumn{2}{|c|}{ Previous treatments for local regional disease } \\
\hline Adrenal surgery & $115(74 \%)$ \\
\hline No adrenal surgery & $35(22 \%)$ \\
\hline Missing & $6(4 \%)$ \\
\hline Adjuvant mitotane & $41(26 \%)$ \\
\hline \multicolumn{2}{|c|}{$\begin{array}{l}\text { Treatments for metastatic disease before bone metastases } \\
\text { diagnosis }\end{array}$} \\
\hline Chemotherapy \pm mitotane & $47(30 \%)$ \\
\hline Mitotane & $14(9 \%)$ \\
\hline \multicolumn{2}{|c|}{ Antineoplastic treatment after bone metastasis diagnosis } \\
\hline Chemotherapy & $62 / 119(40 \%)$ \\
\hline Mitotane (alone) & $16 / 119(10 \%)$ \\
\hline No treatment & $41(26 \%)$ \\
\hline Missing & $37(24 \%)$ \\
\hline \multicolumn{2}{|l|}{ Other treatments } \\
\hline \multirow[t]{2}{*}{ Bone surgery } & $36 / 139(23 \%)$ \\
\hline & Missing $17(11 \%)$ \\
\hline \multirow[t]{2}{*}{ Bone radiation therapy } & $75 / 139(48 \%)$ \\
\hline & Missing $17(11 \%)$ \\
\hline \multirow[t]{2}{*}{ Bisphosphonates } & $31 / 135(23 \%)$ \\
\hline & Missing 21 (13\%) \\
\hline \multirow[t]{2}{*}{ Denosumab ( \pm bisphosphonates) } & $10 / 135$ (7\%) \\
\hline & Missing 21 (13\%) \\
\hline
\end{tabular}

which consisted in either cortisol alone in 46 patients (29\%) or in association with androgens and/or other hormones in 35 patients (23\%), androgens alone in 12 patients (8\%) and estrogen alone in 1 patient (0.6\%). 
One patient had both androgen and mineral corticoid hypersecretion, while in the remaining two patients, the hormones produced in excess were not specified.

Bone was the only metastatic site in 14 patients (9\%), in $91 \%$ of patients BM were associated with other metastatic sites, visceral (liver and lung) in particular.

Previous treatments before the diagnosis of $\mathrm{BM}$ consisted in adrenal surgery in 115 patients (74\%) associated with adjuvant mitotane in 41 patients $(26 \%)$. Forty-seven patients (30\%) had received chemotherapy with or without mitotane or mitotane alone for advanced disease.

After the diagnosis of BM, 62 patients (40\%) received chemotherapy with or without mitotane and 16 patients (10\%) mitotane alone. Forty-one patients (26\%) did not receive any systemic antineoplastic therapy. In the remaining 37 patients (24\%) there were no information on treatment received. Mitotane within the therapeutic range $(14-20 \mathrm{mg} / \mathrm{L})$ was observed in 62 out of 107 available patients (58\%). Thirty-seven out of 135 evaluable patients (27\%) received bone resorption inhibitors: 31 (23\%) bisphosphonates and 6 (4\%) denosumab. Four patients (3\%) received both bisphosphonates and denosumab.

\section{Patient prognosis}

Median follow-up of patients was 12 months (range, 1-217). At the last follow-up examination, 132 patients (85\%) were dead. Median overall survival from the diagnosis of bone metastasis was 11 months (95\% CI: 7-14) (Fig. 1).

Among the 22 potential prognostic factors analyzed in univariate analysis, cortisol hypersecretion and liver metastases were the variables significantly associated with an increased risk of death. Conversely, surgery for primary disease, bone surgery, radiation therapy for BM, the use of bone resorption inhibitors (bisphosphonates and/or denosumab) and serum mitotane levels $>14 \mathrm{mg} / \mathrm{L}$, measured after diagnosis of metastatic disease, were significantly associated with a decreased risk of death. The remaining variables: sex, lung, lymph nodes or other metastases, skeletal complications, such as pathological fractures, hypercalcemia and spinal cord compression, number of metastatic sites failed to show any association with survival.

Moreover, we did not observe any difference in overall survival comparing metacronous (median OS 10.93 months (95\% CI, 6.24-15.62)) versus synchronous BM (median OS 10.86 months (95\% CI, 5.33-16.40),
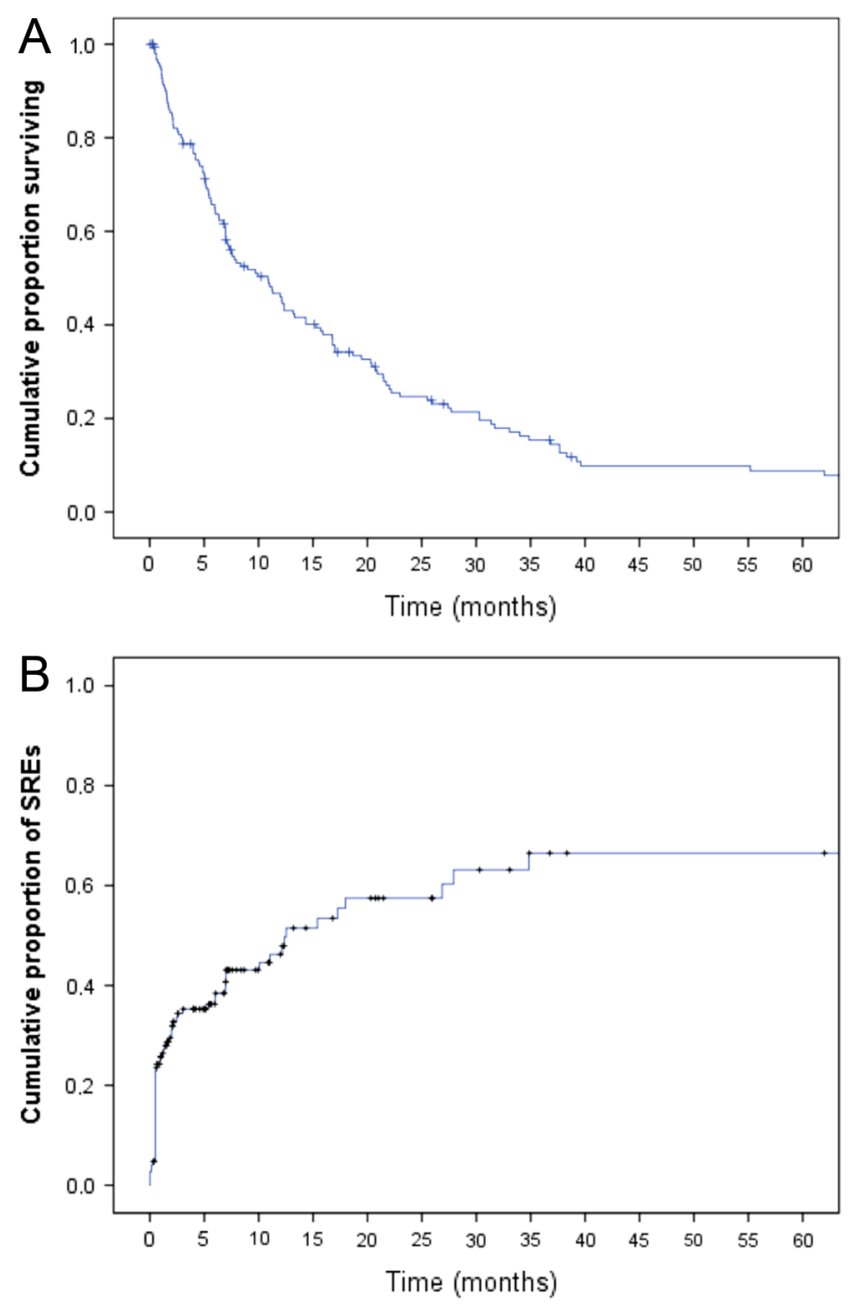

Figure 1

(A) Overall survival of the entire patient population; (B) probability of undergoing adverse skeletal-related events (fractures, spinal cord compression, hypercalcemia).

$P, \quad 0.578$ ) and chemotherapy administration after the diagnosis of $\mathrm{BM}$ was not associated to a survival improvement (Table 2).

Ki67 and Weiss score were available in only 39 and 28 patients respectively. So these two parameters were not included in the statistical analyses.

In multivariate analysis, only cortisol hypersecretion (hazard ratio (HR) 2.240, 95\% CI: $1.188-4.226, P=0.013$ ) maintained a significant association with the death risk.

Mitotane levels and bisphosphonate/denosumab therapy just failed to be significantly associated with overall survival (Table 2).

We further explored the prognostic role of the administration of bisphosphonates/denosumab stratifying patients according to cortisol hypersecretion, 
Table 2 Prognostic factors for overall survival according to univariate and multivariate Cox analysis.

\begin{tabular}{|c|c|c|c|c|c|c|c|}
\hline \multirow[b]{2}{*}{ Overall survival } & \multirow[b]{2}{*}{ Death/n } & \multirow[b]{2}{*}{ Missing } & \multirow[b]{2}{*}{ Total } & \multicolumn{2}{|c|}{ Univariate analysis } & \multicolumn{2}{|c|}{ Multivariate } \\
\hline & & & & $\mathrm{HR}(95 \% \mathrm{Cl})$ & $P$ & $\mathrm{HR}(95 \% \mathrm{Cl})$ & $P$ \\
\hline \multicolumn{8}{|l|}{ Gender } \\
\hline Female & $95 / 105$ & 0 & 105 & $0.82(0.56-1.21)$ & 0.33 & & \\
\hline Male & $36 / 51$ & 0 & 51 & 1 & & & \\
\hline \multicolumn{8}{|l|}{ Age ACC dg } \\
\hline$>50$ & $51 / 64$ & 0 & 64 & $1.40(0.97-2.03)$ & 0.07 & $1.07(0.61-1.89)$ & 0.810 \\
\hline$<50$ & $81 / 92$ & 0 & 92 & 1 & & 1 & \\
\hline \multicolumn{8}{|c|}{ Cortisol hypersecretion } \\
\hline Yes & $75 / 81$ & 0 & 81 & $1.91(1.31-2.79)$ & 0.001 & $2.24(1.19-4.23)$ & 0.013 \\
\hline No & $46 / 61$ & 0 & 61 & 1 & & 1 & Mitotane level \\
\hline$\geq 14$ & $53 / 62$ & 0 & 62 & $0.41(0.27-0.64)$ & 0.000 & $0.61(0.34-1.08)$ & 0.089 \\
\hline$<14$ & $37 / 45$ & 0 & 45 & 1 & & 1 & \\
\hline \multicolumn{8}{|l|}{ Adrenal surgery } \\
\hline Yes & $98 / 115$ & 0 & 115 & $0.56(0.36-0.86)$ & 0.009 & $1.17(0.60-2.29)$ & 0.65 \\
\hline No & $29 / 35$ & 0 & 35 & 1 & & 1 & \\
\hline \multicolumn{8}{|l|}{ Syncronous mets } \\
\hline Yes & $50 / 60$ & 0 & 60 & $1.106(0.774-1.581)$ & 0.58 & & \\
\hline No & $81 / 95$ & 0 & 95 & 1 & & & \\
\hline \multicolumn{8}{|l|}{ Liver mets } \\
\hline Yes & $72 / 83$ & 0 & 83 & $1.637(1.142-2.345)$ & 0.007 & $1.563(0.876-2.788)$ & 0.130 \\
\hline No & $58 / 70$ & 0 & 70 & 1 & & & \\
\hline \multicolumn{8}{|l|}{ Lung mets } \\
\hline Yes & $78 / 91$ & 0 & 91 & 0.987 (0.694-1.403) & 0.94 & & \\
\hline No & $53 / 63$ & 0 & 63 & 1 & & & \\
\hline \multicolumn{8}{|l|}{ Lymphnodes } \\
\hline Yes & $30 / 41$ & 0 & 41 & $1.211(0.797-1.840)$ & 0.37 & & \\
\hline No & $96 / 108$ & 0 & 108 & 1 & & & \\
\hline \multicolumn{8}{|l|}{ Other mets } \\
\hline Yes & $35 / 41$ & 0 & 41 & $0.880(0.590-1.314)$ & 0.53 & & \\
\hline No & $97 / 115$ & 0 & 115 & 1 & & & \\
\hline $0-1$ metastatic site & $67 / 79$ & 0 & 79 & 1 & & & \\
\hline 2 metastatic sites & $39 / 45$ & 0 & 45 & $0.984(0.593-1.515)$ & 0.82 & & \\
\hline$\geq 3$ metastatic sites & $26 / 32$ & 0 & 32 & $1.290(0.769-2.164)$ & 0.33 & & \\
\hline \multicolumn{8}{|c|}{ Pathological fracture } \\
\hline Yes & $36 / 42$ & 0 & 42 & $0.822(0.553-1.222)$ & 0.33 & & \\
\hline No & $82 / 100$ & 0 & 100 & 1 & & & \\
\hline \multicolumn{8}{|l|}{ Spinal compression } \\
\hline Yes & $33 / 43$ & 0 & 43 & $0.946(0.632-1.416)$ & 0.79 & & \\
\hline No & $85 / 99$ & 0 & 99 & 1 & & & \\
\hline \multicolumn{8}{|l|}{ Hypercalcemia } \\
\hline Yes & $1 / 2$ & 0 & 2 & $3.715(0.508-27.192)$ & 0.19 & & \\
\hline No & $117 / 140$ & 0 & 140 & 1 & & & \\
\hline Bone surgery & & & & & & & \\
\hline Yes & $30 / 36$ & 0 & 36 & $0.435(0.281-0.675)$ & 0.000 & $0.663(0.329-1.217)$ & 0.170 \\
\hline No & $85 / 103$ & 0 & 103 & 1 & & & \\
\hline Bone radiation ther & & & & & & & \\
\hline Yes & $61 / 75$ & 0 & 75 & $0.479(0.328-0.700)$ & 0.000 & $0.655(0.346-1.240)$ & 0.194 \\
\hline No & $55 / 64$ & 0 & 64 & 1 & & & \\
\hline Denosumab/bispho & honate & & & & & & \\
\hline Yes & $30 / 37$ & 0 & 37 & $0.562(0.367-0.861)$ & 0.008 & $0.540(0.286-1.020)$ & 0.058 \\
\hline No & $84 / 98$ & 0 & 98 & 1 & & & \\
\hline Chemotherapy $\pm m$ & ane* & & & & & & \\
\hline Yes & $53 / 62$ & 0 & 62 & $1.292(0.732-2.279)$ & 0.377 & & \\
\hline No & $32 / 41$ & 0 & 41 & 1 & & & \\
\hline
\end{tabular}

*First oncological treatment chemio + mito/nothing. 
bone radiation therapy and mitotane serum levels in a multivariate analysis. The effect of bisphosphonate/ denosumab therapy on overall survival did not differ according to the secretion status or whether the patients received bone radiation therapy or not (Fig. 1 and Supplementary materials, see section on supplementary data given at the end of this article).

Conversely bisphosphonate/denosumab therapy was associated with a significantly lower risk of death in patients attaining serum mitotane levels $>14 \mathrm{mg} / \mathrm{L}$ (HR $0.42,95 \%$ CI: $0.22-0.80, P 0.006)$ but not in those who did not (HR 1.00, 95\% CI: 0.47-2.13, P 0.997) (Fig. 2). The difference between the two HRs was statistically significant at the interaction test $(P=0.036)$ after adjusting for cortisol hypersecretion.
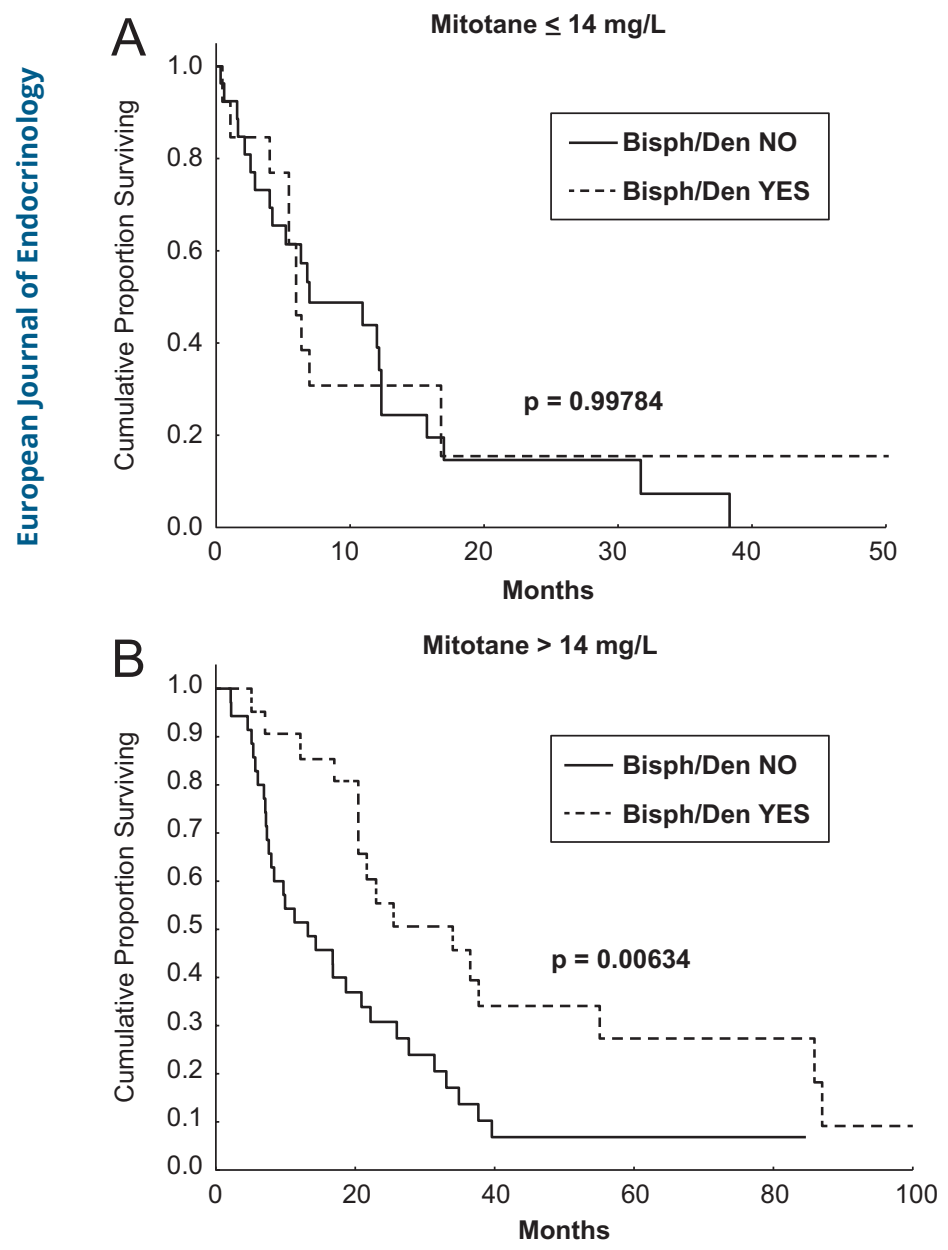

Figure 2

Effects of bisphosphonate/denosumab use on overall survival in (A) patients with mitotane $\leq 14 \mathrm{mg} / \mathrm{L}$; (B) patients with mitotane $>14 \mathrm{mg} / \mathrm{L}$.

\section{Skeletal-related events}

Seventy out of 148 evaluable patients (47\%) developed at least one SRE: 26/148 (17\%) only bone fractures, $1 / 148$ (1\%) only hypercalcemia and 26/148 (17\%) only spinal cord compression. Sixteen patients out of 148 (11\%) presented both pathological fractures and spinal cord compression, one (1\%) patient developed both hypercalcemia and spinal cord compression (Fig. 3A). In 46 patients (29\%), a SRE was detected within 1 month from the diagnosis of BM.

It is likely that SREs led to diagnosis of BM in most of these cases. Thirty-six out of 139 evaluable patients (26\%) underwent bone surgery and 75/139 (54\%) radiation therapy in bone.

The distribution of skeletal events according to cortisol status was 37/75 (49\%) in patients with cortisol hyper secretion (12/75 (16\%) skeletal fractures, 15/75 (20\%) spinal cord compression, 9/75 (12\%) both spinal cord compression and pathological fractures and 1/75 (1\%) both hypercalcemia and spinal cord compression)

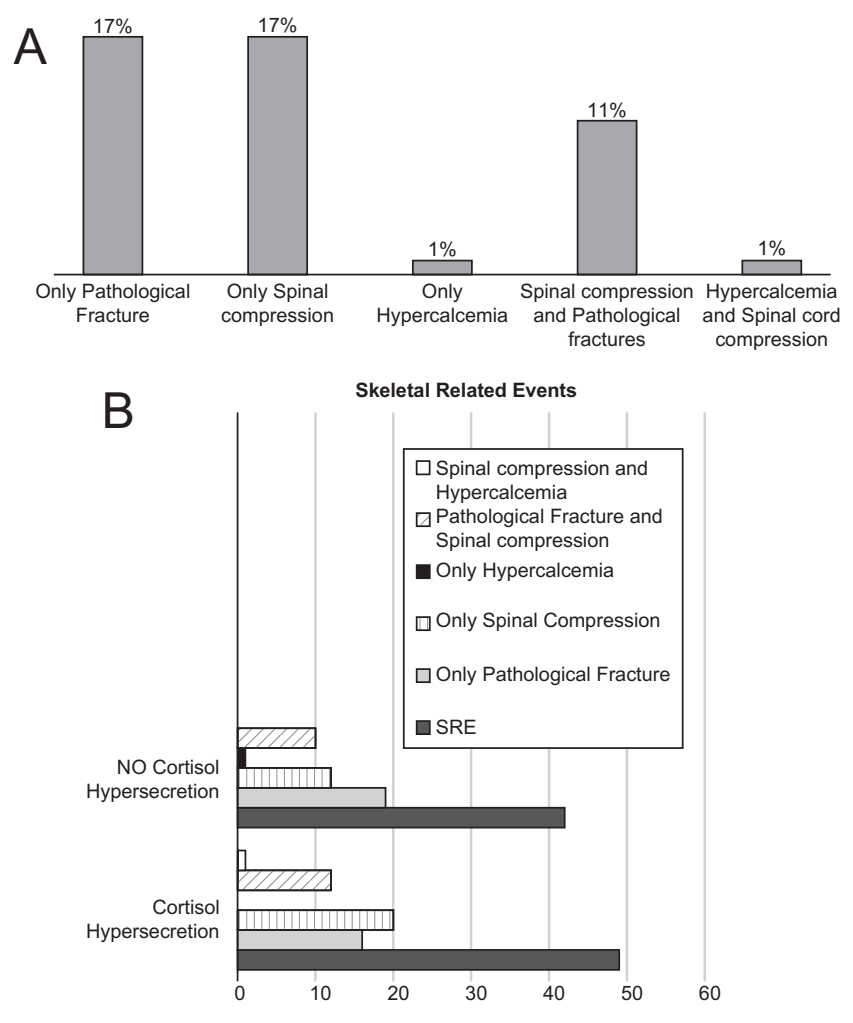

Figure 3

(A) Proportion of patients undergoing skeletal-related events; (B) proportion of patients undergoing skeletal-related events according to the presence or absence of glucocorticoid hypersecretion. 
Table 3 Predictive factors for the time to the occurrence of adverse skeletal events according to univariate and multivariate Cox analysis.

\begin{tabular}{|c|c|c|c|c|c|c|c|}
\hline \multicolumn{2}{|l|}{ Skeletal-related events } & \multirow[b]{2}{*}{ Missing } & \multirow[b]{2}{*}{ Total } & \multicolumn{2}{|c|}{ Univariate analysis } & \multicolumn{2}{|l|}{ Multivariate } \\
\hline & Events $/ n$ & & & $\mathrm{HR}(95 \% \mathrm{Cl})$ & $P$ & $\mathrm{HR}(95 \% \mathrm{Cl})$ & $P$ \\
\hline \multicolumn{8}{|l|}{ Gender } \\
\hline Female & $48 / 99$ & 6 & 105 & $1(0.608-1.690)$ & 0.958 & & \\
\hline Male & $23 / 49$ & 2 & 51 & 1.014 & & & \\
\hline \multicolumn{8}{|l|}{ Age ACC dg } \\
\hline$>50$ & $29 / 86$ & & & $1.267(0.775-2.069)$ & 0.345 & & \\
\hline$<50$ & $27 / 62$ & & & 1 & & & \\
\hline \multicolumn{8}{|l|}{ Cortisol hypersecretion } \\
\hline Yes & $38 / 75$ & 6 & 81 & $1.748(1.019-2.998)$ & 0.043 & $5.848(0.703-48.655)$ & 0.102 \\
\hline No & $24 / 59$ & 2 & 61 & 1 & & 1 & \\
\hline \multicolumn{8}{|l|}{ Mitotane level } \\
\hline$\geq 14$ & $33 / 62$ & 0 & 62 & $0.914(0.489-1.709)$ & 0.778 & & \\
\hline$<14$ & $17 / 45$ & 0 & 45 & 1 & & & \\
\hline \multicolumn{8}{|l|}{ Adrenal surgery } \\
\hline Yes & $51 / 109$ & 6 & 115 & $0.662(0.372-1.175)$ & 0.159 & & \\
\hline No & $17 / 33$ & 2 & 35 & 1 & & & \\
\hline \multicolumn{8}{|l|}{ Synchronous mets } \\
\hline Yes & $28 / 57$ & 3 & 60 & $1.179(0.723-1.921)$ & 0.509 & & \\
\hline No & $43 / 91$ & 4 & 95 & 1 & & & \\
\hline \multicolumn{8}{|l|}{ Liver mets } \\
\hline Yes & $38 / 82$ & 1 & 83 & $1.148(0.705-1.870)$ & 0.578 & & \\
\hline No & $31 / 64$ & 6 & 70 & & & & \\
\hline \multicolumn{8}{|l|}{ Lung mets } \\
\hline Yes & $42 / 89$ & 2 & 91 & $0.974(0.597-1.590)$ & 0.917 & & \\
\hline No & $28 / 58$ & 5 & 63 & 1 & & & \\
\hline \multicolumn{8}{|l|}{ Lymphnodes } \\
\hline Yes & $19 / 39$ & 2 & 41 & $1.353(0.782-2.340)$ & 0.280 & & \\
\hline No & $48 / 104$ & 4 & 108 & 1 & & & \\
\hline \multicolumn{8}{|l|}{ Other mets } \\
\hline Yes & $18 / 37$ & 4 & 41 & $0.869(0.495-1.526)$ & 0.624 & & \\
\hline No & $53 / 111$ & 4 & 115 & 1 & & & \\
\hline 0-1 metastatic site & $35 / 73$ & 6 & 79 & 1 & & & \\
\hline 2 metastatic sites & $22 / 44$ & 1 & 45 & $1.098(0.587-2.054)$ & 0.770 & & \\
\hline 3 or 4 metastatic sites & $14 / 31$ & 1 & 32 & $1.236(0.623-2.453)$ & 0.544 & & \\
\hline \multicolumn{8}{|l|}{ Bone surgery } \\
\hline Yes & $26 / 35$ & 1 & 36 & $1.455(0.861-2.459)$ & 0.161 & & \\
\hline No & 39/97 & 6 & 103 & 1 & & & \\
\hline \multicolumn{8}{|l|}{ Bone radiation therapy } \\
\hline Yes & $41 / 69$ & 6 & 75 & $1.062(0.628-1.796)$ & 0.823 & & \\
\hline No & $25 / 62$ & 2 & 64 & 1 & & & \\
\hline \multicolumn{8}{|c|}{ Denosumab/bisphosphonates } \\
\hline Yes & $26 / 37$ & 0 & 37 & $1.627(0.967-2.737)$ & 0.067 & $1.494(0.261-8.545)$ & 0.652 \\
\hline No & $36 / 97$ & 1 & 98 & 1 & & 1 & \\
\hline \multicolumn{8}{|c|}{ Antineoplastic treatments after BM diagnosis } \\
\hline 0 & $18 / 37$ & 4 & 41 & 1 & & & \\
\hline Mitotane & $6 / 13$ & 3 & 16 & $1.382(0.745-2.564)$ & 0.304 & & \\
\hline Chemotherapy & $23 / 61$ & 1 & 62 & $1.405(0.530-3.725)$ & 0.494 & & \\
\hline
\end{tabular}

and $25 / 59(42 \%)$ in those without hyper secretion $(11 / 59$ skeletal fractures (19\%), 7/59 spinal cord compression (12\%), 6/59 (10\%) both spinal cord compression and pathological fracture, 1/59 (1\%) hypercalcemia) (Fig. 3B).

Only 12 patients out of 156 had pure androgen secretion. Among them 4 out of 12 (30\%) developed an SRE.

The greater proportion of spinal cord compression in patients with cortisol hypersecretion did not attain the statistical significance $(P=0.20)$. Cortisol hypersecretion was significantly associated with a greater risk to develop a SRE in univariate analysis; however, it did not maintain a significant independent role in multivariate analysis (Table 3). We also analyzed the predictive role of several parameters for the occurrence over time of either bone fractures or spinal cord compression assessed separately. As depicted in Supplementary Tables 1 and 2, none of the 
parameters evaluated were associated with bone fractures (Supplementary Table 1), while cortisol hypersecretion was predictive of an increased risk of spinal cord compression (Supplementary Table 2) (HR 2.21, 95\% CI: 1.10-4.44, $P=0.026)$.

\section{Discussion}

This retrospective, multicentric study of the ENSAT network with the cooperation of the MD Anderson Cancer Center retrieved data of a consistent number of ACC patients with BM allowing definition of the survival perspective, the frequency of adverse SREs and to identify prognostic factors affecting the patient outcome.

The results showed that bone involvement from ACC was observed in about $14 \%$ of advanced ACC patients and that bone metastastatization portends a limited survival perspective (median, 11 months). However, the life expectancy of such patients is alike to advanced ACC patients enrolled in the FIRM-ACT trial (14). Bone was the single metastatic site in only $9 \%$ of patients, while in most patients $\mathrm{BM}$ were diagnosed concomitantly to other metastatic sites (visceral metastases in particular). Usually, BM were not synchronous to the primary tumor and metachronous metastases occurred late in the course of disease (15). The number of sites involved, a strong independent prognostic factor in advanced ACC (5), failed to be prognostic in this series. Probably because most cases had multiple sites involved.

Cortisol hypersecretion was the strongest prognostic factor, confirming the negative effect of this condition on patient outcome, as previously reported $(16,17)$. In mitotane-treated patients, blood drug levels above $14 \mathrm{mg} / \mathrm{L}$ were associated with better outcome that just failed to be statistically significant in multivariate analysis $(18,19)$. As to the treatment administered, only $52 \%$ of patients received a specific antineoplastic therapy, $40 \%$ of patients have been already submitted to chemotherapy and mitotane, or both, before the diagnosis of BM, and these patients could have been judged ineligible for further therapies when BM became apparent. However, chemotherapy administered after the diagnosis of BM failed to improve the patient prognosis.

Due to the retrospective nature of this study, we did not have information on patient performance status and co-morbidities, and this is a limitation.

The clinical outcome of ACC patients with BM was frequently complicated by the occurrence of SREs, since $47 \%$ of patients had at least 1 SRE, mainly fractures and spinal cord compression. The proportion of patients with a SRE in this series is higher than that observed in other multicenter retrospective series involving bone metastatic patients from colon (17.8\%) (20), lung (26.4\%) (21) and kidney cancer (24\%) (22). A recent retrospective study showed that thyroid cancer patients with BM had a similar proportion of SREs (43.4\%) to that of the present series (23). It should be noted, however, that bone metastatic patients with thyroid cancer have a quite long survival perspective that predisposes them to develop SREs. In this series, SREs prompted the diagnosis of BM in one-third of cases, suggesting that in many ACC patients the occurrence of an SRE led to diagnosis of BM. SREs were more frequently observed in patients with cortisol hypersecretion, a finding that could be explained by a contributing effect of elevated cortisol levels on bone fragility (24). When the type of SREs were analyzed separately, however, cortisol hypersecretion was associated with a greater risk of spinal cord compression, that is usually due to tumor invasion in the spinal canal, but not with skeletal fractures. These data suggest a major contribution of cortisol secretion in favoring the disease progression in bone. Conversely, hypercalcemia was rare. Hypercalcemia in solid tumors is associated with the ectopic production of parathyroid related peptides (PTHrP) (25). PTHrp was frequently detected in ACC tumors by immunohistochemistry and PTHrp immunostaing was associated with poor prognostic features (26). The potential inhibitory effect of elevated cortisol levels on circulating PTHrP levels (27) could provide a possible explanation on why hypercalcemia in our series was rare despite the frequent PTHrP secretion by ACC (28).

In prospective randomized clinical trials testing the efficacy of bisphosphonates and denosumab in the management of bone metastatic patients $(29,30)$, bone surgery and bone radiation therapy were included in the definition of SRE. In the present series, we adopted a stricter definition because bone surgery and radiation therapy are treatments and not negative events. As a matter of fact, both treatment modalities were associated with an improved survival in univariate analysis.

Bone resorption inhibitors have demonstrated to decrease the frequency of SREs in patients with BM from breast, prostate and lung cancer $(11,12,13)$. In the present series, these drugs were administrated in one third of patients and their use failed to be associated with a reduced incidence of SREs. We do not have information about the date of start of bone resorption inhibitors, the inverse association between the onset of SRE and the use of 
bisfosfonates/denosumab suggest that in most cases these drugs were administered after the onset of the first SRE.

Noteworthy, the administration of bone resorption inhibitors in this study was associated with a longer survival but it failed to attain the statistical significance in multivariate analysis. It is known that these drugs may act as specific cytotoxic agents, as demonstrated by several preclinical studies $(31,32)$ including one on ACC (33) or may influence the prognosis indirectly by inhibiting the activity of the bone metastatic niche and preventing cancer colonization outside the bone microenvironment (31). Interestingly, in the present series, the efficacy of these drugs in improving survival seemed confined in the patient subset attaining mitotane serum levels within the therapeutic range. These data suggest a possible synergism between the two drugs to be confirmed in in vitro and in vivo studies.

The retrospective nature of this study is the main limitation and the statistical analyses performed should be considered explorative and hypothesis generating.

Prospective studies are needed to establish the real benefit of antiresorptive therapies to reduce SRE as well as in improving overall survival of ACC patients.

In conclusion, this multicenter, multinational, retrospective study demonstrates that the appearance of BM complicates dramatically the natural history of ACC, since they are associated with poor prognosis and high risk of SREs. Cortisol hypersecretion was the main negative prognostic parameter and bisphosphonate (or denosumab) administration may be associated with a survival improvement, particularly in patients with mitotane levels within the therapeutic range.

\section{Supplementary data}

This is linked to the online version of the paper at https://doi.org/10.1530/ EJE-19-0026.

\section{Declaration of interest}

Massimo Terzolo has received research grant from HRA and Novartis. Alfredo Berruti has received research grant from Janssen Cilag and honoraria from HRA for advisory board participation. The other authors have nothing to discose.

\section{Funding}

A research grant from Associazione Italiana per la Ricerca sul Cancro (grant number IG17678) to M T.

\section{Acknowledgements}

The authors would like to thank the Dutch Adrenal Network, for providing patient data. The study was sponsored and funded in part by the 'Fondazione Internazionale di Ricerca in Medicina' (FIRM) onlus.

\section{References}

1 Berruti A, Baudin E, Gelderblom H, Haak HR, Porpiglia F, Fassnacht M, Pentheroudakis G \& ESMO Guidelines Working Group. Adrenal cancer: ESMO Clinical Practice Guidelines for diagnosis, treatment and follow-up. Annals of Oncology 201223 (Supplement 7) vii131-vii138. (https://doi.org/10.1093/annonc/mds231)

2 Fassnacht M, Dekkers OM, Else T, Baudin E, Berruti A, de Krijger RR, Haak HR, Mihai R, Assie G \& Terzolo M. European Society of Endocrinology Clinical Practice Guidelines on the management of adrenocortical carcinoma in adults, in collaboration with the European Network for the Study of Adrenal Tumors. European Journal of Endocrinology 2018179 G1-G46. (https://doi.org/10.1530/EJE-180608)

3 Puglisi S, Perotti P, Cosentini D, Roca E, Basile V, Berruti A \& Terzolo M. Decision-making for adrenocortical carcinoma: surgical, systemic, and endocrine management options. Expert Review of Anticancer Therapy 201818 1125-1133. (https://doi.org/10.1080/147 37140.2018.1510325)

4 Lombardi CP, Raffaelli M, Boniardi M, De Toma G, Marzano LA, Miccoli P, Minni F, Morino M, Pelizzo MR, Pietrabissa A et al. Adrenocortical carcinoma: effect of hospital volume on patient outcome. Langenbeck's Archives of Surgery 2012397 201-207. (https:// doi.org/10.1007/s00423-011-0866-8)

5 Libé R, Borget I, Ronchi CL, Zaggia B, Kroiss M, Kerkhofs T, Bertherat J, Volante M, Quinkler M, Chabre O et al. Prognostic factors in stage III-IV adrenocortical carcinomas (ACC): en European Network for the Study of Adrenal Tumor (ENSAT) study. Annals of Oncology 201526 2119-2125. (https://doi.org/10.1093/annonc/ mdv329)

6 Berruti A, Tucci M, Mosca A, Tarabuzzi R, Gorzegno G, Terrone C, Vana F, Lamanna G, Tampellini M, Porpiglia F et al. Predictive factors for skeletal complications in hormone-refractory prostate cancer patients with metastatic bone disease. British Journal of Cancer 2005 93 633-638. (https://doi.org/10.1038/sj.bjc.6602767)

7 Oefelein MG, Ricchiuti V, Conrad W \& Resnick MI. Skeletal fractures negatively correlate with overall survival in men with prostate cancer. Journal of Urology 2002168 1005-1007. (https://doi. org/10.1097/01.ju.0000024395.86788.cc)

8 Sousa S \& Clézardin P. Bone-targeted therapies in cancer-induced bone disease. Calcified Tissue International 2018102 227-250. (https://doi.org/10.1007/s00223-017-0353-5)

9 LeVasseur N, Clemons M, Hutton B, Shorr R \& Jacobs C. Bonetargeted therapy use in patients with bone metastases from lung cancer: a systematic review of randomized controlled trials. Cancer Treatment Reviews 201650 183-193. (https://doi.org/10.1016/j. ctrv.2016.09.013)

10 Saad F, Shore N, Van Poppel H, Rathkopf DE, Smith MR, de Bono JS, Logothetis CJ, de Souza P, Fizazi K, Mulders PF et al. Impact of bonetargeted therapies in chemotherapy-naïve metastatic castrationresistant prostate cancer patients treated with abiraterone acetate: post hoc analysis of study COU-AA-302. European Urology 201568 570-577. (https://doi.org/10.1016/j.eururo.2015.04.032)

11 Rosen LS, Gordon D, Tchekmedyian S, Yanagihara R, Hirsh V, Krzakowski M, Pawlicki M, de Souza P, Zheng M, Urbanowitz G et al. Zoledronic acid versus placebo in the treatment of skeletal metastases in patients with lung cancer and other solid tumors: a phase III, double-blind, randomized trial - the zoledronic acid Lung Cancer and Other Solid Tumors Study Group. Journal of Clinical Oncology 200321 3150-3157. (https://doi.org/10.1200/JCO.2003.04.105)

12 Lipton A, Fizazi K, Stopeck AT, Henry DH, Brown JE, Yardley DA, Richardson GE, Siena S, Maroto P, Clemens M et al. Superiority of denosumab to zoledronic acid for prevention of skeletal-related events: a combined analysis of 3 pivotal, randomised, phase 3 trials. European Journal of Cancer 201248 3082-3092. (https://doi. org/10.1016/j.ejca.2012.08.002) 
13 Coleman RE. Efficacy of zoledronic acid and pamidronate in breast cancer patients: a comparative analysis of randomized phase III trials. American Journal of Clinical Oncology 200225 (6 Supplement 1) S25-S31. (https://doi.org/10.1097/00000421200212001-00005)

14 Fassnacht M, Terzolo M, Allolio B, Baudin E, Haak H, Berruti A, Welin S, Schade-Brittinger C, Lacroix A, Jarzab B et al. Combination chemotherapy in advanced adrenocortical carcinoma. New England Journal of Medicine 2012366 2189-2197. (https://doi.org/10.1056/ NEJMoa1200966)

15 Ettaieb MH, Duker JC, Feelders RA, Corssmit EP, Menke-Van Der Houven Van Oordt CW, Timmers HJ, Kerstens MN, Wilmink JW, Zelissen PM, Havekes B et al. Synchronous vs metachronous metastases in adrenocortical carcinoma: an analysis of the Dutch Adrenal Network. Hormones and Cancer 20167 336-344.

16 Berruti A, Fassnacht M, Haak H, Else T, Baudin E, Sperone P, Kroiss M, Kerkhofs T, Williams AR, Ardito A et al. Prognostic role of overt hypercortisolism in completely operated patients with adrenocortical cancer. European Urology 201465 832-838. (https://doi.org/10.1016/j. eururo.2013.11.006)

17 Abiven G, Coste J, Groussin L, Anract P, Tissier F, Legmann P, Dousset B, Bertagna X \& Bertherat J. Clinical and biological features in the prognosis of adrenocortical cancer: poor outcome of cortisolsecreting tumors in a series of 202 consecutive patients. Journal of Clinical Endocrinology and Metabolism 200691 2650-2655. (https:// doi.org/10.1210/jc.2005-2730)

18 Hermsen IG, Fassnacht M, Terzolo M, Houterman S, den Hartigh J, Leboulleux S, Daffara F, Berruti A, Chadarevian R, Schlumberger M et al. Plasma concentrations of $\mathrm{o}, \mathrm{p}^{\prime} \mathrm{DDD}, \mathrm{o}, \mathrm{p}^{\prime} \mathrm{DDA}$, and $\mathrm{o}, \mathrm{p}^{\prime} \mathrm{DDE}$ as predictors of tumor response to mitotane in adrenocortical carcinoma: results of a retrospective ENS@T multicenter study. Journal of Clinical Endocrinology and Metabolism 201196 1844-1851. (https://doi.org/10.1210/jc.2010-2676)

19 Terzolo M, Baudin AE, Ardito A, Kroiss M, Leboulleux S, Daffara F, Perotti P, Feelders RA, deVries JH, Zaggia B et al. Mitotane levels predict the outcome of patients with adrenocortical carcinoma treated adjuvantly following radical resection. European Journal of Endocrinology 2013169 263-270. (https://doi.org/10.1530/EJE-130242)

20 Santini D, Tampellini M, Vincenzi B, Ibrahim T, Ortega C, Virzi V, Silvestris N, Berardi R, Masini C, Calipari N et al. Natural history of bone metastasis in colorectal cancer: final results of a large Italian bone metastases study. Annals of Oncology 201223 2072-2077. (https://doi.org/10.1093/annonc/mdr572)

21 Santini D, Barni S, Intagliata S, Falcone A, Ferraù F, Galetta D, Moscetti L, La Verde N, Ibrahim T, Petrelli F et al. Natural history of non-small-cell lung cancer with bone metastases. Scientific Reports 20155 18670. (https://doi.org/10.1038/srep18670)

22 Santini D, Procopio G, Porta C, Ibrahim T, Barni S, Mazzara C, Fontana A, Berruti A, Berardi R, Vincenzi B et al. Natural history of malignant bone disease in renal cancer: final results of an Italian bone metastasis survey. PLoS ONE 20138 e83026. (https://doi. org/10.1371/journal.pone.0083026)
23 Mazziotti G, Formenti AM, Panarotto MB, Arvat E, Chiti A, Cuocolo A, Dottorini ME, Durante C, Agate L, Filetti S et al. Reallife management and outcome of thyroid carcinoma-related bone metastases: results from a nationwide multicenter experience. Endocrine 201859 90-101. (https://doi.org/10.1007/s12020-0171455-6)

24 Chiodini I, Vainicher CE, Morelli V, Palmieri S, Cairoli E, Salcuni AS, Copetti M \& Scillitani A. MECHANISMS IN ENDOCRINOLOGY: Endogenous subclinical hypercortisolism and bone: a clinical review. European Journal of Endocrinology 2016175 R265-R282. (https://doi. org/10.1530/EJE-16-0289)

25 VanHouten JN, Yu N, Rimm D, Dotto J, Arnold A, Wysolmerski JJ $\&$ Udelsman R. Hypercalcemia of malignancy due to ectopic transactivation of the parathyroid hormone gene. Journal of Clinical Endocrinology and Metabolism 200691 580-583. (https://doi. org/10.1210/jc.2005-2095)

26 Jouinot A \& Bertherat J. MANAGEMENT of ENDOCRINE DISEASE: Adrenocortical carcinoma: differentiating the good from the poor prognosis tumors. European Journal of Endocrinology $2018 \mathbf{1 7 8}$ R215-R230. (https://doi.org/10.1530/EJE-18-0027)

27 Guerreiro PM, Rotllant J, Fuentes J, Power DM \& Canario AV. Cortisol and parathyroid hormone-related peptide are reciprocally modulated by negative feedback. General and Comparative Endocrinology 2006 148 227-235). (https://doi.org/10.1016/j.ygcen.2006.03.004)

28 Mazziotti G, Formenti AM, Adler RA, Bilezikian JP, Grossman A, Sbardella E, Minisola S \& Giustina A. Glucocorticoid-induced osteoporosis: pathophysiological role of GH/IGF-I and PTH/vitamin $\mathrm{D}$ axes, treatment options and guidelines. Endocrine $2016 \mathbf{5 4}$ 603-611. (https://doi.org/10.1007/s12020-016-1146-8)

29 Fizazi K, Carducci M, Smith M, Damião R, Brown J, Karsh L, Milecki P, Shore N, Rader M, Wang H et al. Denosumab versus zoledronic acid for treatment of bone metastases in men with castration-resistant prostate cancer: a randomised, double-blind study. Lancet 2011377 813-822. (https://doi.org/10.1016/S01406736(10)62344-6)

30 Schröder J, Fietz T, Köhler A, Petersen V, Tesch H, Spring L, Fleitz A, Jänicke M, Marschner N \& TMK-Group (Tumour Registry Breast Cancer). Treatment and pattern of bone metastases in 1094 patients with advanced breast cancer - results from the prospective German Tumour Registry Breast Cancer cohort study. European Journal of Cancer 201779 139-148. (https://doi.org/10.1016/j.ejca.2017.03.031)

31 Clezardin P. Potential anticancer properties of bisphosphonates: insights from preclinical studies. Anti-Cancer Agents in Medicinal Chemistry 201212 102-113. (https://doi. org/10.2174/187152012799014977)

32 Fragni M, Bonini SA, Stabile A, Bodei S, Cristinelli L, Simeone C, Zani D, Spano PF, Berruti A, Memo M et al. Inhibition of survivin is associated with zoledronic acid-induced apoptosis of prostate cancer cells. Anticancer Research 201636 913-920.

33 Fassnacht M, Franke A, Dettling A, Hahner S, Zink M, Wudy S \& Allolio B. Clodronate inhibits adrenocortical cell proliferation and P450c21 activity. Journal of Endocrinology 2002174 509-516. (https:// doi.org/10.1677/joe.0.1740509)

Received 9 January 2019

Revised version received 14 March 2019

Accepted 21 March 2019 